\title{
Ocular toxoplasmosis - an update and review of the literature
}

\author{
Alessandra G Commodaro', Rubens N Belfort ${ }^{1,2}$, Luiz Vicente Rizzo ${ }^{3}$, Cristina Muccioli', \\ Claudio Silveira ${ }^{4}$, Miguel N Burnier Jr ${ }^{1,2}$, Rubens Belfort Jr ${ }^{1 /+}$
}

\author{
${ }^{1}$ Instituto da Visão, Universidade Federal de São Paulo, Rua Botucatu 820, 04038-000 São Paulo, SP, Brasil ${ }^{2}$ Henry C Witelson Ocular \\ Pathology Laboratory, McGill University, Montreal, Canadá ${ }^{3}$ Albert Einstein Jewish Institute for Education and Research, São Paulo, SP, Brasil \\ ${ }^{4}$ Clínica Silveira, Erechim, RS, Brasil
}

Ocular toxoplasmosis is the most common cause of posterior uveitis worldwide. The infection can be acquired congenitally or postnatally and ocular lesions may present during or years after the acute infection occur. Current treatment controls ocular infection and inflammation, but does not prevent recurrences. We present a review and update on ocular toxoplasmosis and address misconceptions still found in the current medical literature.

Key words: ocular toxoplasmosis - diagnosis - treatment and ocular lesions

Ocular toxoplasmosis is caused by the protozoan parasite Toxoplasma gondii. Infections may be acquired congenitally or through the ingestion of uncooked and infected meat, contaminated vegetables or water (Silveira et al. 1988).

$T$. gondii infects up to a third of the world's population and is responsible for the majority of infectious uveitis (intra ocular inflammation) cases. In some countries, up to $50 \%$ of all cases of posterior uveitis in a given population are attributable to toxoplasmosis (Soheilian et al. 2004, Vallochi et al. 2005).

The population structure of $T$. gondii is highly clonal. There are three predominant clonal lineages in North America and Europe, namely I, II and III. The lineages are based on murine model virulence studies (Howe \& Sibley 1995). It has been suggested that the type II clonal lineage of $T$. gondii may be responsible for the majority of acquired ocular lesions, while type I may be more frequently seen in congenital toxoplasmosis. Recently, it has been shown that type I as well as atypical strains may play an important role in acquired infection (Howe \& Sibley 1995, Belfort-Neto et al. 2007).

Type II strains appear to be responsible for the majority of symptomatic human cases in France and the United States (Nowakowska et al. 2006), while types I and III are found in only $10 \%$ and $9 \%$ of Toxoplasma isolates from patients, respectively (Howe et al. 1997).

In Brazil, type I strains appear to be responsible for ocular infections in human patients (Vallochi et al. 2005). De Moura et al. (2006) showed that parasites isolated from contaminated water in the Southern state of Paraná were type I. Another recent publication analyzing samples from Brazilian patients suggests a cloning diversity

Financial support: FAPESP, PAOF, CNPQ, CAPES, FADA-UNIFESP + Corresponding author: clinbelf@uol.com.br

Received 10 October 2008

Accepted 4 December 2008 when compared with strains from North America and Europe (Khan et al. 2006). The city of Erechim, in the South of Brazil, has a $17 \%$ prevalence of ocular toxoplasmosis, and type I T. gondii predominates (Jones et al. 2006). The genotypes of $T$. gondii strains isolated from São Paulo and Erechim (Brazil) were highly atypical when compared with the previously described cloning lineages reported in the literature (Khan et al. 2006).

Genotyping of $T$. gondii in 24 chickens from the Amazon, Brazil, indicated that 14 were type I and 10 were type III, confirming that strains in Brazil are divergent from European or North American strains (Dubey et al. 2006).

In Erechim, samples from porcine tongues and diaphragms were obtained in both large and small abattoirs and tested for $T$. gondii. The results indicated a high prevalence of infection and suggested that unusual genotypes of $T$. gondii are also found in Brazil among domesticated pigs (Belfort-Neto et al. 2007). In that area, according to an epidemiological survey, risk factors for acquiring toxoplasmosis include eating undercooked meat, working in the garden or yard more than once per week, eating raw, cured, dried or smoked meat and being a male (Jones et al. 2006).

The genetic makeup of $T$. gondii is more complex than the three-strain theory and unusual genotypes may contribute to various clinical outcomes of toxoplasmosis in different localities. Variant alleles have also been associated with severity of pathology. The study of parasite genetic backgrounds is important for understanding the establishment of ocular disease (Vallochi et al. 2008).

\section{Ocular manifestations and diagnosis}

Toxoplasmic retinochoroiditis is often seen in settings of congenital or postnatally acquired disease as a result of acute infection or recurrence (Nussenblatt \& Belfort 1994, Montoya \& Remington 1996). This disease typically affects the posterior pole of a single eye and the lesions can be solitary, multiple or satellite to a pigmented retinal scar (Fig. 1).

Active lesions present as grey-white focuses of retinal necrosis with adjacent choroiditis, vasculitis, haemorrhage and vitreitis (Figs 2-4). Cicatrization occurs from 


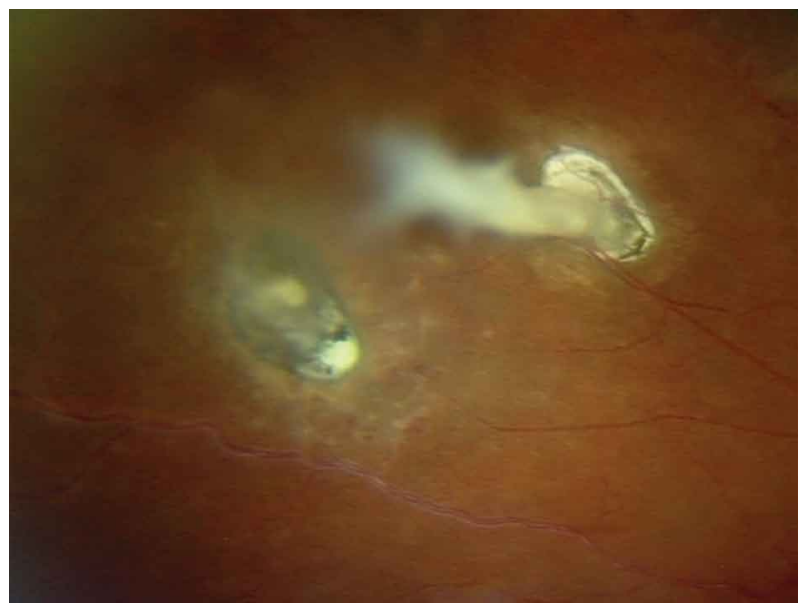

Fig. 1: inactive old ocular toxoplasmosis lesions with vitreous strand and vasculitis.

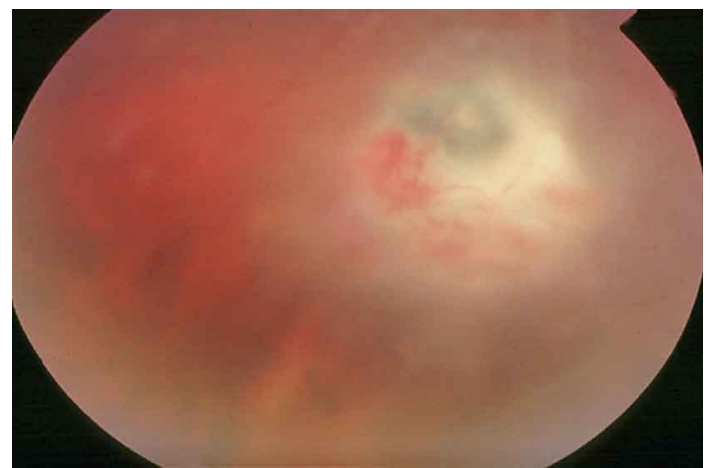

Fig. 2: retinal scar with typical features of recurrent ocular toxoplasmosis.

the periphery towards the centre, with variable pigmentary changes. Anterior uveitis is another common finding, with mutton-fat keratic precipitates, cells and flare, and posterior synechiae (Nussenblatt \& Belfort 1994).

The retina is the primary site of $T$. gondii infection in the eye, but the choroid, vitreous and anterior chamber are also involved. The choroid is secondarily affected, although choroidal lesions do not occur in the absence of retinal infection. An intense secondary iridocyclitis may also be present (Nussenblatt \& Belfort 1994, Holland 2004). In addition, the optic nerve head can also be involved in ocular toxoplasmosis (Eckert et al. 2007) (Fig. 5).

Elderly or immunosuppressed patients may present with more aggressive bilateral or multifocal disease (Fig. 6). Elderly patients recently infected with $T$. gondii may have a higher prevalence of ocular involvement. Other atypical presentations include punctate outer retinal toxoplasmosis, retinal vasculitis, retinal vascular occlusions, rhegmatogenous with serous retinal detachments, unilateral pigmentary retinopathy mimicking retinitis pigmentosa, neuroretinitis and additional forms of optic neuropathy, peripheral retinal necrosis and scleritis (Smith \& Cunningham 2002, Bonfioli \& Orefice 2005).

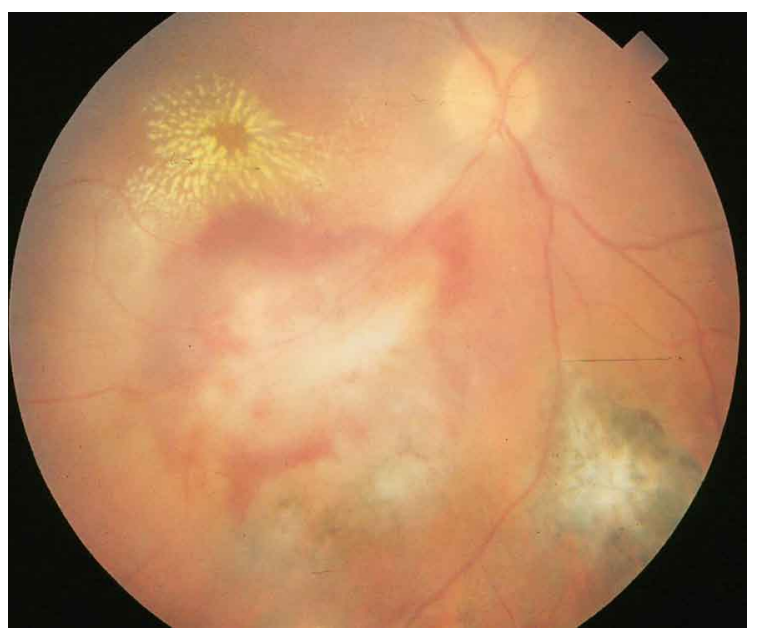

Fig. 3: ocular toxoplasmosis with old pigmented scar and recurrence inferior to the macula.

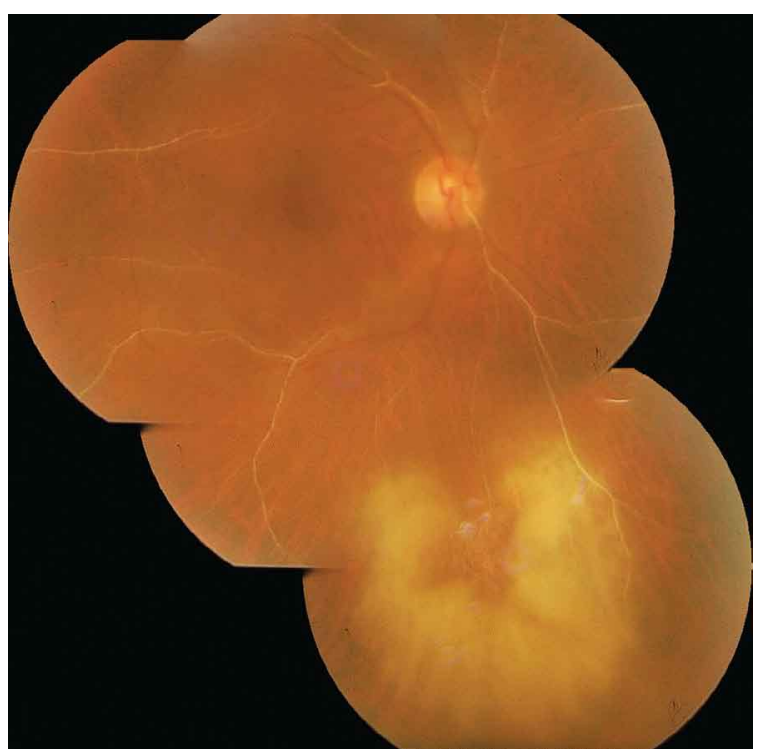

Fig. 4: inferior area of retinochoroiditis and diffuse vasculitis.

Ocular complications seen more frequently in children, include choroidal neovascularisation, cataract, glaucoma, optic nerve atrophy and retinal detachment (Bosch-Driessen et al. 2000). An association between ocular toxoplasmosis and Fuchs' heterochromic cyclitis has been described (Toledo de Abreu et al. 1982) and confirmed by several researchers (Schwab 1991, La Hey \& Baarsma 1993, Ganesh et al. 2004).

The appearance of toxoplasmic retinochoroiditis lesions varies. The duration and intensity may be related to the host, parasite, or environmental factors (Holland et al. 1996). The genotype of the infecting parasite appears to be an important determinant of disease severity in immunocompetent patients (Holland 2004). 
Retinal vasculitis and associated inflammatory reactions may be the lone ophthalmic disorder during the early stages of a newly acquired $T$. gondii infection. Later development of retinitis or scars consistent with toxoplasmic retinochoroiditis in the same eyes suggests that the initial isolated inflammation may have been caused by the parasites. These cases may have implications for understanding the original source of retinal infection in patients who have recurrent toxoplasmic retinochoroiditis and could have implications for novel treatments of newly acquired $T$. gondii infections (Silveira et al.2001).

Recurrent toxoplasmic retinochoroiditis is not associated with systemic symptoms and the risk of recurrence may be influenced by patient age. Ocular lesions may first develop many years after $T$. gondii infection and are often asymptomatic (Nussenblatt \& Belfort 1994).

Transplacental transmission of $T$. gondii to the foetus during pregnancy is another important route of infection. The mother can transmit toxoplasmosis to the foetus if

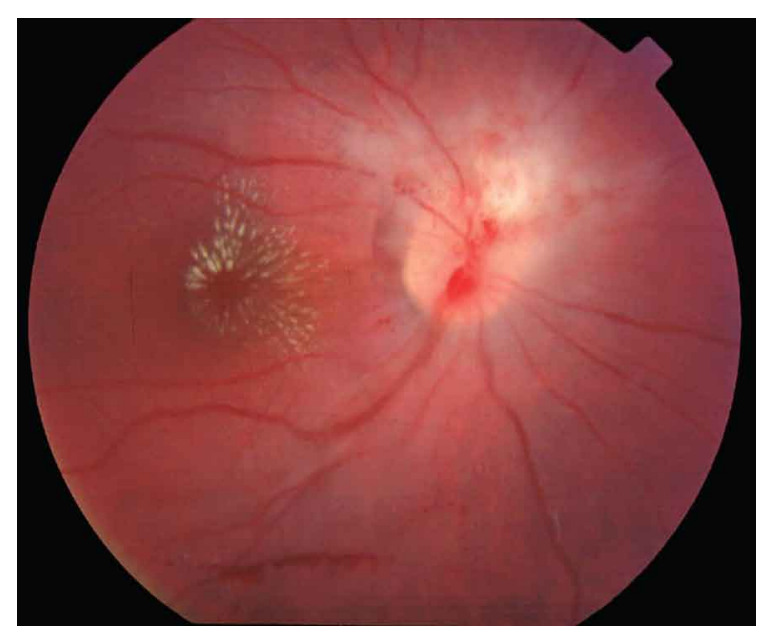

Fig. 5: optic disk involvement with macular exudates in a case of ocular toxoplasmosis.

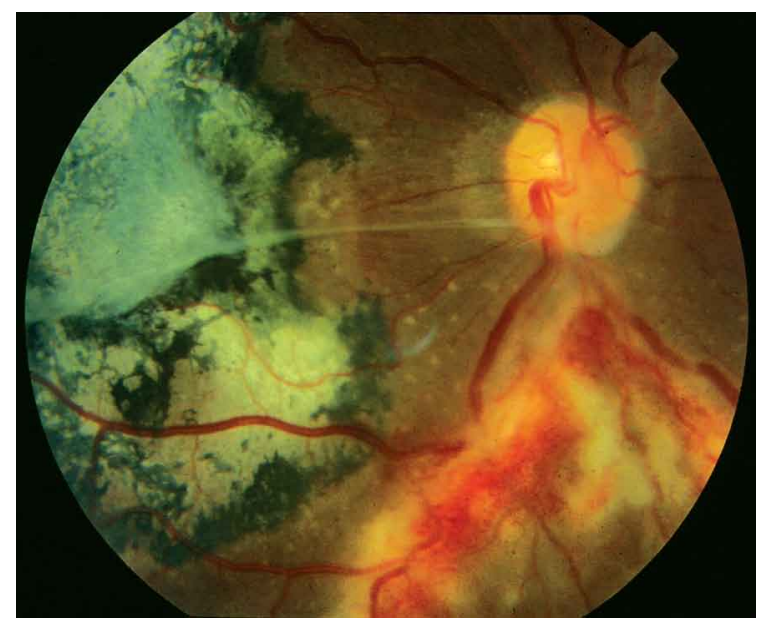

Fig. 6: toxoplasmic scar and active CMV retinitis in a patient with AIDS. infected primarily by $T$. gondii during pregnancy or a few months prior to conception (Montoya \& Liesenfeld 2004). The foetal infection can result in visual loss, hearing loss, mental and psychomotor retardation, seizures, haematological abnormalities, hepatosplenomegaly and/ or death (Montoya \& Remington 2008). Retinochoroidal scars are the most characteristic manifestation of a congenital or prenatal infection (Mets \& Chhabra 2008) (Fig. 7). Mothers who become infected during the first trimester of gestation have a decreased risk of congenital transmission, but more severe consequences for the foetus when compared with the third trimester (Montoya \& Remington 2008). Paediatricians, parents and elder children with congenital infections should be aware that late-onset retinal lesions can occur many years after birth, but the overall ocular prognosis of congenital toxoplasmosis is satisfactory when the infection is identified early and treated accordingly (Wallon et al. 2004).

Severe bilateral impairment occurred in $9 \%$ of children with congenital toxoplasmic retinochoroiditis. Half of the children with a posterior pole lesion and one in six of those with peripheral lesions alone were visually impaired in the affected eye (Tan et al. 2007). Numerous children with congenital toxoplasmosis have substantial retinal damage at birth and consequent loss of vision. Nevertheless, vision may be remarkably good, even in the presence of large macular scars. Active lesions become quiescent with treatment and may recur at any age (Mets et al. 1997).

In one study evaluating 430 children treated for congenital toxoplasmosis, ocular involvement was present in $30 \%$ of the cohort after a median follow-up of 12 years. The overall functional prognosis of congenital toxoplasmosis was better than would be predicted on the basis of literature findings, with only two of the 130 children suffering bilateral visual impairment (Kodjikian et al. 2006).

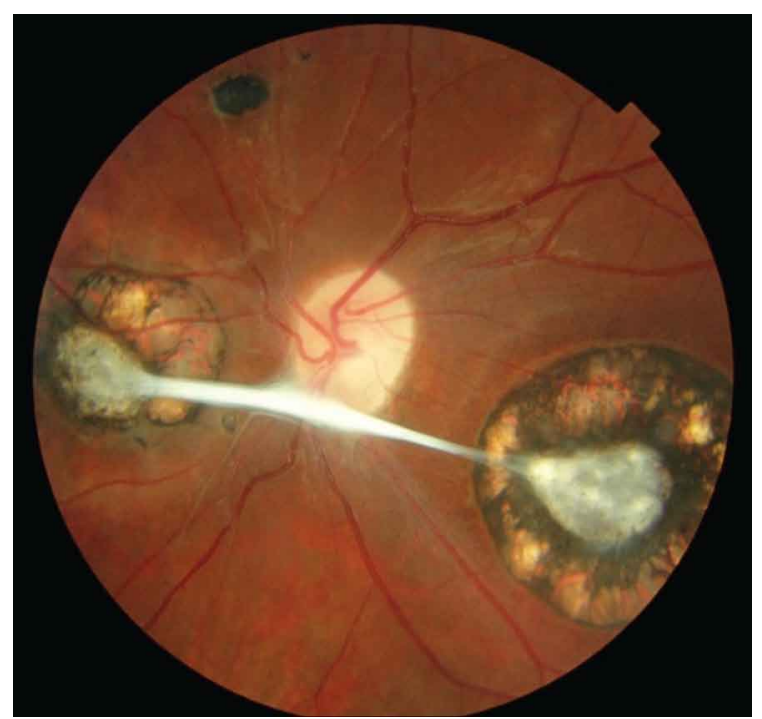

Fig. 7: retinal scars linked by vitreous strand in congenital toxoplasmosis. 
Although it is classically known that only during acute infection the mother could transmit the infection to the foetus, there are a few reports supporting the possibility that chronically infected women may be transmitting the disease congenitally (Silveira et al. 2003).

The diagnosis of ocular toxoplasmosis is typically clinical. There is no reliable diagnostic test to identify toxoplasmic uveitis. The presence of anti $T$. gondii IgG antibodies does not confirm the toxoplasmic aetiology, but a negative IgG generally discards the possibility. Such antibodies can often persist at high titers for years after the acute infection and there is a high prevalence of such antibodies in the general population (Ongkosuwito et al. 1999).

Pathological diagnosis of ocular toxoplasmosis can be established by identifying the cysts in biopsies stained with haematoxylin and eosin, polyclonal or monoclonal antibodies by immunohistochemistry (Rao \& Font 1977), or by polymerase chain reaction (PCR) (Brezin et al. 1990). Histologically, ocular toxoplasmosis typically presents as extensive granulomatous inflammatory infiltration of the choroid and areas of necrosis of Bruch's membrane (Belfort et al. 2008, unpublished observations).

$T$. gondii DNA has been identified in ocular tissue sections of patients with presumed toxoplasmic retinochoroiditis using PCR techniques, even when typical tissue cysts are not identified during histopathologic examination (Brézin et al. 1990, Ongkosuwito et al. 1999).

Examination of vitreous fluid using PCR in patients where toxoplasmosis is considered in the differential diagnosis but in whom the presentation is atypical, is a useful diagnostic aid (Montoya et al. 1999, Rothova et al. 2008). To facilitate genotyping of $T$. gondii in vitreous fluid of patients with severe or atypical ocular toxoplasmosis, PCR followed by restriction fragment length polymorphism assays were developed (Grigg et al. 2001).

One study compared three biological methods, immunoblotting/Western blotting, the calculation of the Goldmann-Witmer coefficient and PCR for the diagnosis of ocular toxoplasmosis in the aqueous humor and serum samples. The authors showed that the combination of all three techniques improved the sensitivity of diagnosis to $97 \%$ (Fekkar et al. 2008).

Alternatively, nested-PCR (nPCR) can be a reliable diagnostic technique for ocular toxoplasmosis because of the amount of specimen required, speed, cost effectiveness, high sensibility and high specificity to detect of T. gondii DNA in the intraocular fluids (Calderaro et al. 2006, Mahalakshmiet al. 2006).

More recently, real-time PCR has been replacing nPCR as a rapid and sensitive technique for quantitatively evaluating ocular samples for the presence of infectious pathogens (Lin et al. 2000, Dworkin et al. 2002, Rothova et al. 2008).

Laboratory confirmation of the diagnosis is also thwarted by marked individual variations in the time elapsing between the onset of clinical symptoms and the activation of specific antibody production. This difficulty results in a high proportion of false negative results (Garweg 2005).

\section{Treatment of ocular toxoplasmosis}

Ocular toxoplasmosis therapy includes antimicrobial drugs with or without the presence of corticosteroids. Several drugs have been proposed including pyrimethamine, sulfadiazine, spiramycin, clindamycin and trimethoprim-sulfamethoxazol (Pleyer et al. 2007, Antoniazzi et al. 2008).

Results of a study comparing three drug combinations: (i) association of pyrimethamine, sulphadiazine and corticosteroids; (ii) association of clindamycin, sulphadiazine and corticosteroids; (iii) association of cotrimoxazole (trimethoprim and sulphamethoxazole) and corticosteroids, showed no difference in the resolution of inflammatory activities. However the most common side effects were associated with pyrimethamine medication and included hematologic complications, such as thrombocytopenia and leucopenia, despite folinic acid supplementation (Rothova et al. 1989). The same group studied in 1993 showed a reduction in size of the retinal inflammatory lesion for $49 \%$ of the pyrimethamine-treated patients (17 of 35) compared to $20 \%$ of the untreated patients $(8$ of 41). However, the most frequent occurrence of side effects was also associated with pyrimethamine medication (26\%, 9 of 35) (Rothova et al. 1993).

The combination of pyrimethamine, sulfadiazine and corticosteroids, which is considered "classic" or specific therapy for ocular toxoplasmosis, is the most common drug combination currently used to treat toxoplasmosis (Montoya \& Liesenfeld 2004).

Patients with active toxoplasmosis may also be treated with trimethoprim-sulfamethoxazole (Bactrim), with or without adjunctive clindamycin and prednisone for 4-6 weeks. Trimethoprim-sulfamethoxazole appears to be a safe and effective substitute for sulfadiazine, pyrimethamine and folinic acid in treating for the treatment of ocular toxoplasmosis (Opremcak et al. 1992, Soheilian et al. 2005).

The pyrimethamine and azithromycin drug combination was shown to be similar to the standard treatment with pyrimethamine and sulfadiazine. However, the frequency and severity of adverse effects was significantly lower with the regimen containing pyrimethamine and azithromycin. Multidrug therapy containing the combination of pyrimethamine and azithromycin appears to be an acceptable alternative treatment for sight-threatening ocular toxoplasmosis (Bosch-Driessen et al. 2002).

The causes of recurrences in ocular toxoplasmosis remain unknown. The causes may be related to the rupture of the dormant retinal cyst (Abreu et al. 1987) or toxoplasma circulating in peripheral blood (Silveira et al., unpublished observations). Recurrent toxoplasmic retinochoroiditis remains a major health crisis and can be associated with severe morbidity if the disease extends to structures critical for vision, including the macula and optic disk. Severe morbidity may also occur if there is damage to the eye from inflammation or if there are complications such as retinal detachment or neovascularisation. In patients with frequent recurrences, long-term intermittent treatment with trimethoprim $(160 \mathrm{mg}) /$ sulfamethoxazole $(800 \mathrm{mg})$, one tablet three 
times a week reduced the rate of recurrent toxoplasmic retinochoroiditis from 23.8-6.6\% (Silveira et al. 2002).

Traditional short-term treatment of active toxoplasmic retinochoroiditis lesions does not prevent subsequent recurrences. Various short-term therapeutic approaches had no effect on visual outcomes or future recurrence rates, with the exception of a poor visual outcome for patients who received corticosteroids without anti parasitic drugs (Bosch-Driessen et al. 2002). Studies have yet to confirm the relationship between systemic corticosteroid use and reactivation of toxoplasmosis (Morhun et al. 1996).

Intravitreal clindamycin injection and possibly steroids may be indicated for patients that have contraindication of systemic therapy specific for toxoplasmosis (Aggio et al. 2006, Sobrin et al. 2007). Sobrin et al (2007) showed that intravitreal clindamycin injection, alone or in conjunction with pars plana vitrectomy, was associated with resolution of toxoplasmic retinochoroiditis. On the other hand, intravitreal injections of clindamycin and dexamethasone (Kishore et al. 2001) with subconjunctival injections of clindamycin (Colin \& Harie 1989) appear to be an interesting useful alternative in the choice of an anti-toxoplasmic ocular therapy.

Treatment with spiramycin should be initiated immediately after diagnosis of recently acquired maternal infection (Montoya \& Liesenfeld 2004). The literature shows the lack of efficacy of short-term treatments for ocular disease as well as the long-term prenatal treatments on foetal transmission rate and the severity of congenital disease (Rothova 2003).

Ocular toxoplasmosis remains a disease in which most concepts are unfortunately not based on scientific evidence. Treatments often change according to induction and seduction of speakers and investigators instead of objective findings based on reasoning and deduction. Little is known, and much less of what is known is true.

\section{REFERENCES}

Abreu MT, Belfort Jr R, Oréfice F 1987. Toxoplasmose ocular. In F Oréfice, R Belfort Jr. Uveites, Roca, São Paulo, p. 211-230.

Aggio FB, Muccioli C, Belfort R Jr 2006. Intravitreal triamcinolone acetonide as an adjunct in the treatment of severe ocular toxoplasmosis. Eye 20: 1080-1082.

Antoniazzi E, Guagliano R, Meroni V, Pezzotta S, Bianchi PE 2008. Ocular impaiment of toxoplasmosis. Parasitologia 50: 35-36.

Belfort-Neto R, Nussenblatt V, Rizzo L, Muccioli C, Silveira C, Nussenblatt R, Khan A, Sibley LD, Belfort R Jr 2007. High prevalence of unusual genotypes of Toxoplasma gondii infection in pork meat samples from Erechim, Southern Brazil. An Acad Bras Cienc 79: 111-114.

Belfort RN, Rasmussen S, Kherani A, Lodha N, Williams G, Fernandes BF, Burnier Jr MN 2008. Bilateral progressive necrotizing retinichoroiditis in a immunocompromised patient: histopathologic diagnosis. Acta Ophthalmol, in press.

Bonfioli AA, Orefice F 2005. Toxoplasmosis. Semin Ophthalmol 20: 129-141.

Bosch-Driessen LH, Berendschot TT, Ongkosuwito JV, Rothova A 2002. Ocular toxoplasmosis: clinical features and prognosis of 154 patients. Ophthalmology 109: 869-878.

Bosch-Driessen LH, Karimi S, Stilma JS, Rothova A 2000. Retinal detachment in ocular toxoplasmosis. Ophthalmology 107: 36-40.
Brézin AP, Egwuagu CE, Burnier M Jr, Silveira C, Mahdi RM, Gazzinelli RT, Belfort R Jr, Nussenblatt RB 1990. Identification of Toxoplasma gondii in paraffin-embedded sections by the polymerase chain reaction. Am J Ophthalmol 110: 599-604.

Calderaro A, Piccolo G, Gorrini C, Peruzzi S, Zerbini L, Bommezzadri S, Dettori G, Chezzi C 2006. Comparison between two real-time PCR assays and a nested-PCR for the detection of Toxoplasma gondii. Acta Biomed 77: 75-80.

Colin J, Harie JC 1989. Presumed toxoplasmic chorioretinitis: comparative study of treatment with pyrimethamine and sulfadiazine or clindamycin. J Fr Ophtalmol 12: 161-165.

De Moura L, Bahia-Oliveira LM, Wada MY, Jones JL, Tuboi SH, Carmo EH, Ramalho WM, Camargo NJ, Trevisan R, Graça RM, da Silva AJ, Moura I, Dubey JP, Garrett DO 2006. Waterborne toxoplasmosis, Brazil, from field to gene. Emerg Infect Dis 12: 326-329.

Dubey JP, Gennari SM, Labruna MB, Camargo LM, Vianna MC, Marcet PL, Lehmann T 2006. Characterization of Toxoplasma gondii isolates in free-range chickens from Amazon, Brazil. J Parasitol 92: 36-40.

Dworkin LL, Gibler TM, Van Gelder RN 2002. Real-time quantitative polymerase chain reaction diagnosis of infectious posterior uveitis. Arch Ophthalmol 120: 1534-1539.

Eckert GU, Melamed J, Menegaz B 2007. Optic nerve changes in ocular toxoplasmosis. Eye 21: 746-751.

Fekkar A, Bodaghi B, Touafek F, Le Hoang P, Mazier D, Paris L 2008. Comparison of immunoblotting, calculation of the GoldmannWitmer coefficient, and real-time PCR using aqueous humor samples for diagnosis of ocular toxoplasmosis. J Clin Microbiol 46: 1965-1967.

Ganesh SK, Sharma S, Narayana KM, Biswas J 2004. Fuchs' heterochromic iridocyclitis following bilateral ocular toxoplasmosis. Ocul Immunol Inflamm 12: 75-77.

Garweg JG 2005. Department of determinants of immunodiagnostic success in human ocular toxoplasmosis. Parasite Immunol 27: 61-68.

Grigg ME, Ganatra J, Boothroyd JC, Margolis TP 2001. Unusual abundance of atypical strains associated with human ocular toxoplasmosis. J Infect Dis 184: 633-639.

Holland GN 2004. Ocular toxoplasmosis: a global reassessment. Part II: disease manifestations and management. Am J Ophthalmol 137: 1-17.

Holland GN, O’Connor GR, Belfort Jr R, Remington JS 1996. Toxoplasmosis. In JS Pepose, GN Holland, KR Wilhelmus. Ocular infection \& immunity, Mosby-Year Book, St. Louis, p. 1183-1223.

Howe DK, Honoré S, Derouin F, Sibley LD 1997. Determination of genotypes of Toxoplasma gondii strains isolated from patients with toxoplasmosis. J Clin Microbiol 35: 1411-1414.

Howe DK, Sibley DL 1995. Toxoplasma gondii comprises three clonal lineages: correlation of parasite genotype with human disease. J Infect Dis 172: 1561-1566.

Jones JL, Muccioli C, Belfort R Jr, Holland GN, Roberts JM, Silveira C 2006. Recently acquired Toxoplasma gondii infection, Brazil. Emerg Infect Dis 12: 582-587.

Khan A, Jordan C, Muccioli C, Vallochi AL, Rizzo LV, Belfort R Jr, Vitor RW, Silveira C, Sibley LD 2006. Genetic divergence of Toxoplasma gondii strains associated with ocular toxoplasmosis, Brazil. Emerg Infect Dis 12: 942-949.

Kishore K, Conway MD, Peyman GA 2001. Intravitreal clindamycin and dexamethasone for toxoplasmic retinochoroiditis. Ophthalmic Surg Lasers 32: 183-192. 
Kodjikian L, Wallon M, Fleury J, Denis P, Binquet C, Peyron F, Garweg JG 2006. Ocular manifestations in congenital toxoplasmosis. Graefes Arch Clin Exp Ophthalmol 244: 14-21.

La Hey E, Baarsma GS 1993. Contralateral active ocular toxoplasmosis in Fuchs' heterochromic cyclitis. Br J Ophthalmol 77: 455-456.

Lin MH, Chen TC, Kuo TT, Tseng CC, Tseng CP 2000. Real-time PCR for quantitative detection of Toxoplasma gondii. J Clin Microbiol 38: 4121-4125.

Mahalakshmi B, Therese KL, Madhavan HN, Biswas J 2006. Diagnostic value of specific local antibody production and nucleic acid amplification technique-nested polymerase chain reaction (nPCR) in clinically suspected ocular toxoplasmosis. Ocul Immunol Inflamm 14: 105-112.

Mets MB, Chhabra MS 2008. Eye manifestations of intrauterine infections and their impact on childhood blindness. Surv Ophthalmol 53: 95-111.

Mets MB, Holfels E, Boyer KM, Swisher CN, Roizen N, Stein L, Stein M, Hopkins J, Withers S, Mack D, Luciano R, Patel D, Remington JS, Meier P, McLeod R 1997. Eye manifestations of congenital toxoplasmosis. Am J Ophthalmol 123: 1-16.

Montoya JG, Liesenfeld O 2004. Toxoplasmosis. Lancet 363: 1965-1976.

Montoya JG, Parmley S, Liesenfeld O, Jaffe GJ, Remington JS 1999. Use of the polymerase chain reaction for diagnosis of ocular toxoplasmosis. Ophthalmology 106: 1554-1563.

Montoya JG, Remington JS 1996. Toxoplasmic chorioretinitis in the setting of acute acquired toxoplasmosis. Clin Infect Dis 23: 277-282.

Montoya JG, Remington JS 2008. Management of Toxoplasma gondii infection during pregnancy. Clin Infect Dis 47: 554-566.

Morhun PJ, Weisz JM, Elias SJ, Holland GN 1996. Recurrent ocular toxoplasmosis in patients treated with systemic corticosteroids. Retina 16: 383-387.

Nowakowska D, Colón I, Remington JS, Grigg M, Golab E, Wilczynski J, Sibley LD 2006. Genotyping of Toxoplasma gondii by multiplex PCR and peptide-based serological testing of samples from infants in Poland diagnosed with congenital toxoplasmosis. J Clin Microbiol 44: 1382-1389.

Nussenblatt RB, Belfort R Jr 1994. Ocular toxoplasmosis. An old disease revisited. JAMA 271: 304-307.

Ongkosuwito JV, Bosch-Driessen EH, Kijlstra A, Rothova A 1999. Serologic evaluation of patients with primary and recurrent ocular toxoplasmosis for evidence of recent infection. Am J Ophthalmol 128: 407-412.

Opremcak EM, Scales DK, Sharpe MR 1992. Trimethoprim-sulfamethoxazole therapy for ocular toxoplasmosis. Ophthalmology 99: 920-925.

Pleyer U, Torun N, Liesenfeld O 2007. Ocular toxoplasmosis. Ophthalmologe 104: 603-615.

Rao NA, Font RL 1977. Toxoplasmic retinochoroiditis: electron-microscopic and immunofluorescence studies of formalin-fixed tissue. Arch Ophthalmol 95: 273-277.

Rothova A 2003. Ocular manifestations of toxoplasmosis. Curr Opin Ophthalmol 14: 384-388.

Rothova A, Buitenhuis HJ, Meenken C, Baarsma GS, Boen-Tan TN, de Jong PT, Schweitzer CM, Timmerman Z, de Vries J, Zaal MJ, Kijlstra A 1989. Therapy of ocular toxoplasmosis. Int Ophthalmol 13: 415-419.
Rothova A, de Boer JH, Ten Dam-van Loon NH, Postma G, de Visser L, Zuurveen SJ, Schuller M, Weersink AJ, van Loon AM, de Groot-Mijnes JD 2008. Usefulness of aqueous humor analysis for the diagnosis of posterior uveitis. Ophthalmology 115: 306-311.

Rothova A, Meenken C, Buitenhuis HJ, Brinkman CJ, Baarsma GS, Boen-Tan TN, de Jong PT, Klaassen-Broekema N, Schweitzer CM, Timmerman Z, Vries J de, Zaal MJW, Kijlstra A 1993. Therapy for ocular toxoplasmosis. Am J Ophthalmol 115: 517-523.

Schwab IR 1991. The epidemiologic association of Fuchs' heterochromic iridocyclitis and ocular toxoplasmosis. Am J Ophthalmol 111: 356-362.

Silveira C, Belfort R Jr, Burnier M Jr, Nussenblatt R 1988. Acquired toxoplasmic infection as the cause of toxoplasmic retinochoroiditis in families. Am J Ophthalmol 106: 362-364.

Silveira C, Belfort R Jr, Muccioli C, Abreu MT, Martins MC, Victora C, Nussenblatt RB, Holland GN 2001. A follow-up study of Toxoplasma gondii infection in Southern Brazil. Am J Ophthalmol 131: 351-354.

Silveira C, Belfort R Jr, Muccioli C, Holland GN, Victora CG, Horta BL, Yu F, Nussenblatt RB 2002. The effect of long-term intermittent trimethoprim/sulfamethoxazole treatment on recurrences of toxoplasmic retinochoroiditis. Am J Ophthalmol 134: 41-46.

Silveira C, Ferreira R, Muccioli C, Nussenblatt R, Belfort R Jr 2003. Toxoplasmosis transmitted to a newborn from the mother infected 20 years earlier. Am J Ophthalmol 136: 370-381.

Smith JR, Cunningham ET Jr 2002. Atypical presentations of ocular toxoplasmosis. Curr Opin Ophthalmol 13: 387-392.

Sobrin L, Kump LI, Foster CS 2007. Intravitreal clindamycin for toxoplasmic retinochoroiditis. Retina 27: 952-957.

Soheilian M, Heidari K, Yazdani S, Shahsavari M, Ahmadieh H, Dehghan M 2004. Patterns of uveitis in a tertiary eye care center in Iran. Ocul Immunol Inflamm 12: 297-310.

Soheilian M, Sadoughi MM, Ghajarnia M, Dehghan MH, Yazdani S, Behboudi H, Anisian A, Peyman GA 2005. Prospective randomized trial of trimethoprim/sulfamethoxazole versus pyrimethamine and sulfadiazine in the treatment of ocular toxoplasmosis. Ophthalmology 112: 1876-1882.

Tan HK, Schmidt D, Stanford M, Teär-Fahnehjelm K, Ferret N, Salt A, Gilbert R 2007. Risk of visual impairment in children with congenital toxoplasmic retinochoroiditis. Am J Ophthalmol 144: 648-653.

Toledo de Abreu M, Belfort R Jr, Hirata PS 1982. Fuchs' heterochromic cyclitis and ocular toxoplasmosis. Am J Ophthalmol 93: 739-744.

Vallochi AL, Goldberg AC, Falcai A, Ramasawmy R, Kalil Filho J, Silveira C, Belfort R Jr, Rizzo LV 2008. Molecular markersos susceptibility to ocular toxoplasmosis, host and guest behaving badly. Clin Ophthalmol 4: 1-12.

Vallochi AL, Muccioli C, Martins MC, Silveira C, Belfort R Jr, Rizzo LV 2005. The genotype of Toxoplasma gondii strains causing ocular toxoplasmosis in humans in Brazil. Am J Ophthalmol 139: 350-361.

Wallon M, Kodjikian L, Binquet C, Garweg J, Fleury J, Quantin C, Peyron F 2004. Long-term ocular prognosis in 327 children with congenital toxoplasmosis. Pediatrics 113: 1567-1572. 